\title{
Sorting nexin 12 interacts with BACE1 and regulates BACE1-mediated APP processing
}

Yonghao Zhao ${ }^{1,2+}$, Yunshu Wang ${ }^{1,2+}$, Jiaye Yang ${ }^{1,2+}$, Xin Wang ${ }^{3}$, Yingjun Zhao ${ }^{1,2}$, Xian Zhang ${ }^{1}$ and Yun-wu Zhang ${ }^{\text {* }}$

\begin{abstract}
Background: $\beta$-site APP cleaving enzyme 1 (BACE1) cleaves $\beta$-amyloid precursor protein (APP) to initiate the production of $\beta$-amyloid $(A \beta)$, the prime culprit in Alzheimer's disease (AD). Dysregulation of the intracellular trafficking of BACE1 may affect $A \beta$ generation, contributing to $A D$ pathology. In this study, we investigated whether BACE1 trafficking and BACE1-mediated APP processing/A 3 generation are affected by sorting nexin 12 (SNX12), a member of the sorting nexin (SNX) family that is involved in protein trafficking regulation.

Results: Herein, we find that SNX12 is widely expressed in brain tissues and is mainly localized in the early endosomes. Overexpression of SNX12 does not affect the steady-state levels of APP, BACE1 or $\gamma$-secretase components, but dramatically reduces the levels of A $\beta$, soluble APP $\beta$ and APP $\beta$-carboxyl terminal fragments. Downregulation of SNX12 has the opposite effects. Modulation of SNX12 levels does not affect $\gamma$-secretase activity or in vitro $\beta$-secretase activity. Further studies reveal that SNX12 interacts with BACE1 and downregulation of SNX12 accelerates BACE1 endocytosis and decreases steady-state level of cell surface BACE1. Finally, we find that the SNX12 protein level is dramatically decreased in the brain of AD patients as compared to that of controls.

Conclusion: This study demonstrates that SNX12 can regulate the endocytosis of BACE1 through their interaction, thereby affecting $\beta$-processing of APP for A $\beta$ production. The reduced level of SNX12 in AD brains suggests that an alteration of SNX12 may contribute to AD pathology. Therefore, inhibition of BACE1-mediated $\beta$-processing of APP by regulating SNX12 might serve as an alternative strategy in developing an AD intervention.
\end{abstract}

Keywords: $\beta$-amyloid, $\beta$-amyloid precursor protein, $\beta$-site APP cleaving enzyme 1, Alzheimer's disease, Intracellular trafficking, Sorting nexin 12.

\section{Background}

A major pathological hallmark of Alzheimer's disease (AD) is the formation of senile plaques in the brain. The major components of senile plaques are heterogeneous small peptides called $\beta$-amyloid $(A \beta)[1]$. A $\beta$ peptides are derived from the $\beta$-amyloid precursor protein (APP) through sequential proteolytic cleavages; first by $\beta$-secretase and then by $\gamma$-secretase. $\beta$-cleavage of APP generates a soluble APP $\beta(\operatorname{sAPP} \beta)$ fragment and a membrane-associated APP $\beta$-carboxyl terminal fragment $(\beta C T F)$. The latter can then be cleaved by $\gamma$-secretase to release $A \beta . \gamma$-secretase is a high molecular weight

\footnotetext{
* Correspondence: yunzhang@xmu.edu.cn.

${ }^{\dagger}$ Equal contributors

'Fujian Provincial Key Laboratory of Neurodegenerative Disease and Aging Research, College of Medicine, Xiamen University, Xiamen, Fujian 361005,

People's Republic of China

Full list of author information is available at the end of the article
}

complex that consists of presenilin 1 (PS1) or presenilin 2 (PS2), nicastrin, APH1 and PEN-2. Alternatively, APP can be cleaved by $\alpha$-secretase within the $A \beta$ sequence to release soluble APP $\alpha$ (sAPP $\alpha$ ), which is neuroprotective, precluding $A \beta$ generation [1]. Accumulating evidence has shown that overproduction/accumulation of $A \beta$ peptides in vulnerable brain regions is a primary cause in the pathogenesis of AD [2-4]. Therefore, a dysregulation of the proteins involved in $A \beta$ generation, including the altered intracellular trafficking/subcellular localization of them, may increase $A \beta$ generation and lead to disease pathogenesis.

The type I transmembrane aspartyl protease, $\beta$-site APP cleaving enzyme 1 (BACE1), is the putative $\beta$-secretase [5-8]. Because its optimal activity requires an acidic environment, BACE1 is mainly localized in the early Golgi, late Golgi/early endosomes, and endosomes. In addition, BACE1 can be found at the cell surface [6,9-12]. Although

\section{Biomed Central}


several proteins have been found to interact with BACE1 and regulate its intracellular trafficking, such as reticulon/ Nogo [13-15], Golgi-localized $\gamma$-ear-containing ARFbinding (GGA) [16-18] and sorting nexin 6 (SNX6) [19], the detailed mechanism underlying BACE1 trafficking regulation has yet to be fully elucidated.

Sorting nexins (SNXs) are a diverse group of cellular trafficking proteins that are unified by the presence of a phospholipid-binding (PX) motif. The ability of SNXs to bind specific phospholipids, as well as their propensity to form protein-protein complexes, suggests a role for these proteins in membrane trafficking and protein sorting [20-22]. Recently, some SNX members have been found to mediate APP processing/A $\beta$ generation through regulating trafficking of $\mathrm{AD}$ associated proteins: SNX17 can interact with APP in the early endosome and downregulation of SNX17 leads to reduced steady-state levels of APP with a concomitant increase in A $\beta$ production [23]. SNX33 can bind to the endocytic GTPase dynamin and overexpression of SNX33 reduces the rate of APP endocytosis in a dynamin-dependent manner, so that APP is subjected to increased $\alpha$-cleavage in cell surface [24]. Moreover, SNX6 can associate with BACE1 and a reduction of SNX6 results in elevated steady-state levels of BACE1 as well as increased retrograde transport of BACE1 in the endocytic pathway, increasing $A \beta$ generation [19]. However, the functional roles of other SNX proteins, especially their involvement in $\mathrm{AD}$, deserve further scrutiny.

In the present study, we demonstrate that another SNX member, SNX12, can interact with BACE1 and affects its intracellular trafficking, thus mediating $\beta$-processing of $\mathrm{APP}$ in $\mathrm{A} \beta$ production.

\section{Results}

\section{SNX12 affects the level of secreted $A \beta$}

Several SNX family members have been found to modulate $\mathrm{A} \beta$ generation through different mechanisms. Herein, we studied whether several other SNX proteins can also affect $A \beta$ generation. Our results showed that in HEK293 cells stably expressing human APP Swedish mutations (HEK-APP $\mathrm{Swe}_{\text {) }}$, overexpression of one SNX protein, SNX12, dramatically decreased the level of secreted $A \beta$ without affecting the level of full-length APP (Figure 1A). When the level of SNX12 was downregulated by RNAi, the level of full-length APP was not altered but the level of secreted $A \beta$ was significantly increased (Figure 1B). To confirm the regulation of $A \beta$ by SNX12 in primary neurons, we downregulated SNX12 using lentivirus infection in primary neurons derived from APP/PS1/tau triple transgenic mice [25] and found that the levels of $A \beta 40$ and $A \beta 42$ secreted by primary neurons were indeed significantly increased upon downregulation of SNX12 (Figure 1C).

\section{SNX12 is expressed in the brain and localized in early endosomes}

Information on the features and function of SNX12 is very limited. Recently one study reported that SNX12 is widely expressed in the adult mouse central nervous system and thus suggested that SNX12 might regulate neurite formation during cerebral cortical development [26]. Herein, we found that SNX12 is abundantly expressed in mouse cerebrum and cerebellum in addition to other tissues (Figure 2A). Further analysis showed that the expression levels of SNX12 are similar in cortex, hippocampus, cerebellum and midbrain (Figure 2B). Since the major function of the SNX family proteins is thought to be associated with endocytosis, endosomal sorting, endosomal signaling, etc., we speculated that SNX12 may be mainly localized in endosomal compartments. We transfected SNX12-EGFP into HeLa cells and studied the localization of SNX12 in different endosomal compartments by immunofluorescence. The results showed that SNX12 co-localized well with an early endosome marker, EEA1, but not with a late endosome marker, cd63 (Figure 2C), indicating an early endosome localization of SNX12.

\section{SNX12 does not affect $\gamma$-secretase activity}

To determine how SNX12 affects $A \beta$, we first investigated whether SNX12 affects $\gamma$-secretase. The results showed that neither overexpression (Figure 3A) nor downregulation (Figure 3B) of SNX12 altered the protein levels of presenilin 1 amino-terminal fragment (NTF) and nicastrin (NCT), two major components of $\gamma$-secretase. Notch is another major substrate of $\gamma$-secretase. When we overexpressed Notch $\mathrm{N} \Delta \mathrm{E}$, which lacks the ectodomain of Notch1 and can be processed in a ligand-independent manner by $\gamma$-secretase to produce NICD [27], we found that overexpression of SNX12 did not affect the $\gamma$-cleavage of Notch $\mathrm{N} \Delta \mathrm{E}$ for NICD production (Figure 3C). In addition, we overexpressed APP $\beta C T F$ (C99), the direct substrate of $\gamma$-secretase, in HEK cells to avoid the interference of $\beta$-cleavage, and found that overexpression of SNX12 did not affect the generation of $A \beta 40$ or $A \beta 42$ (Figure 3D). Together, these results suggest that SNX12 does not affect the activity of $\gamma$-secretase.

\section{SNX12 affects the $\beta$-processing of APP but not in vitro $\beta$-secretase activity}

Next, we studied whether SNX12 affects the $\beta$-cleavage of APP. Upon overexpression of SNX12, we found that although the total level of BACE1 was not altered, the levels of both APP $\beta C T F$ and SAPP $\beta$, the two direct products of the $\beta$-cleavage of APP, were markedly decreased (Figure 4A). Downregulation of SNX12 increased the levels of APP $\beta C T F$ and $\operatorname{SAPP} \beta$ without affecting the 

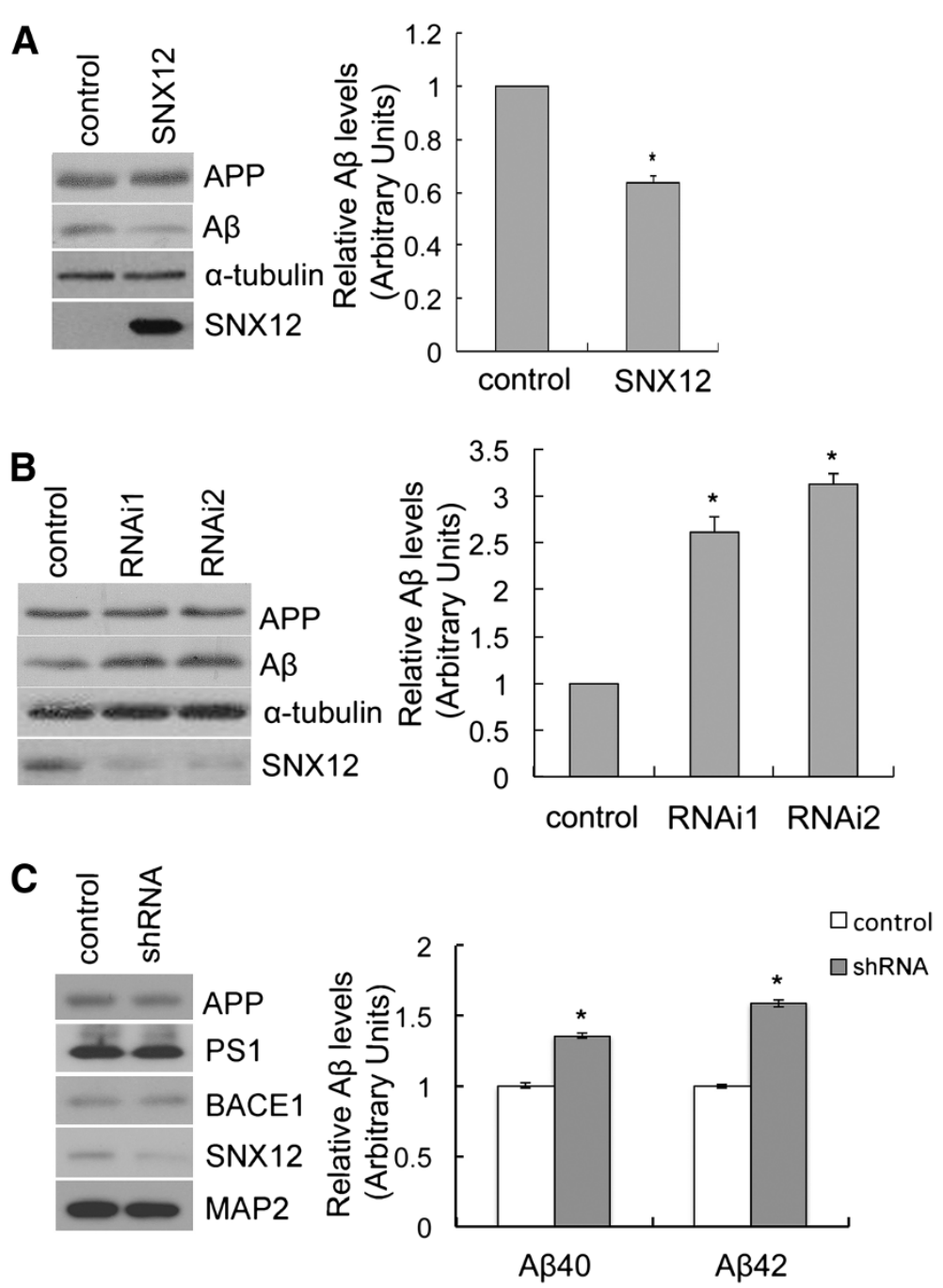

Figure 1 SNX12 regulates $\mathbf{A} \beta$ generation. HEK-APP $_{\text {swe }}$ cells were transfected with $(\mathbf{A})$ SNX12 and control plasmids, or (B) two SNX12 siRNAs (1 and 2) and a control scrambled siRNA. A in conditioned media and total APP and SNX12 in cell lysates were analyzed by Western blot. The levels of $A \beta$ were quantified by densitometry for comparison. $N=3^{*}: p<0.05$. (C) Primary neurons derived from APP/PS1/tau triple transgenic mice at postnatal day 0 were infected with SNX12 shRNA or control lentiviral particles for $72 \mathrm{~h}$. Neuron lysates were analyzed for APP, PS1-NTF, BACE1, SNX12 and MAP2 by Western blot. Secreted $A \beta 40$ and A 42 in conditioned media were quantified by ELISA. The levels of $A \beta 40$ and $A \beta 42$ were normalized to those of controls (set as one arbitrary units) for comparison. $\mathrm{N}=3{ }^{*}: p<0.05$.

level of BACE1 (Figure 4B). APP $\triangle$ C57 lacks the last 57 carboxyl-terminal amino acids of APP and cleavage of APP $\triangle C 57$ by $\beta$-secretase leads to direct production of $\mathrm{A} \beta 42$. We found that in cells expressing human APP $\triangle C 57$, overexpression of SNX12 significantly reduced the level of secreted human A $\beta 42$ (Figure $4 \mathrm{C}$ ). Together, these results suggest that SNX12 affects the $\beta$-processing of APP. However, when SH-SY5Y cells transfected with SNX12 and control plasmid were compared for in vitro activity of BACE1 using a commercial kit, we found no differences between them (Figure 4D), suggesting that SNX12 does not affect the general enzymatic activity of BACE1.

\section{SNX12 interacts with BACE1 but not APP}

Since SNX12 does not affect the level/activity of BACE1, SNX12 may modulate the $\beta$-cleavage of APP through different mechanisms. Because we found that SNX12 is localized in early endosomes and BACE1 has been reported to also be localized in early endosomes, we cotransfected SNX12-EGFP and BACE1-HA into HeLa cells and carried out immunofluorescence studies. The results showed that SNX12 co-localized with BACE1 (Figure 5A). In addition, in cells overexpressing SNX12Myc and BACE1-HA, an anti-HA antibody pulled down SNX12, indicating an interaction between SNX12 and BACE1 (Figure 5B). However, in cells overexpressing 

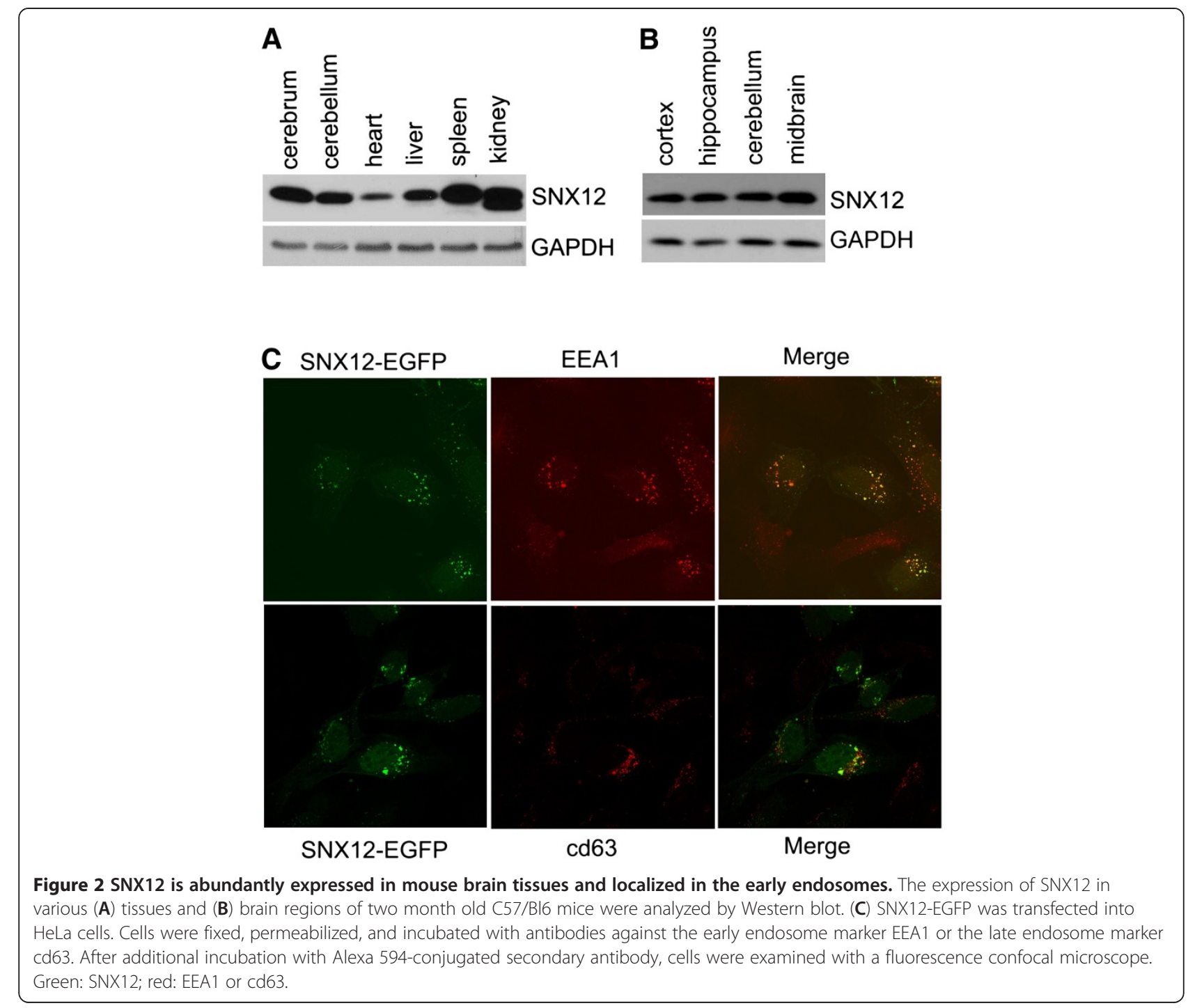

SNX12-Myc and APP, an anti-APP antibody (369) could not pull down SNX12, indicating that SNX12 does not interact with APP (Figure 5C). Moreover, we carried out co-immunoprecipitation between endogenous SNX12 and endogenous BACE1 in SH-SY5Y cells and found that an anti-SNX12 antibody pulled down BACE1 and an anti-BACE1 antibody (689) pulled down SNX12, confirming the interaction between the two (Figure 5D).

\section{SNX12 regulates the endocytosis of BACE1}

Since the endosomal compartment is a major site for the BACE1 cleavage of APP and A $\beta$ generation, SNX12 might mediate the endocytosis of BACE1 through their interaction and thus affect the $\beta$-processing of APP. To address this, we carried out a cell surface protein biotinylation assay and found that upon downregulation of SNX12, the level of cell surface BACE1 was markedly decreased, whereas the levels of cell surface APP, total
APP and total BACE1 were not affected (Figure 6A). Moreover, we studied endocytosis of cell surface BACE1. Under same conditions, an observable endocytosis of BACE1 in control cells occurred at about 15 min after chasing, whereas in cells with SNX12 downregulation, an observable endocytosis of BACE1 occurred early at 5 min after chasing (Figure 6B), suggesting that downregulation of SNX12 can accelerate the endocytosis of BACE1.

The level of SNX12 is decreased in the brain of AD patients

Finally, we detected the level of SNX12 in the brain of $\mathrm{AD}$ patients and age/sex matched controls. The results showed that the level of SNX12 was dramatically decreased in the brains of AD patients over that in controls (Figure 7), suggesting a direct link between SNX12 changes and AD pathology. 
A
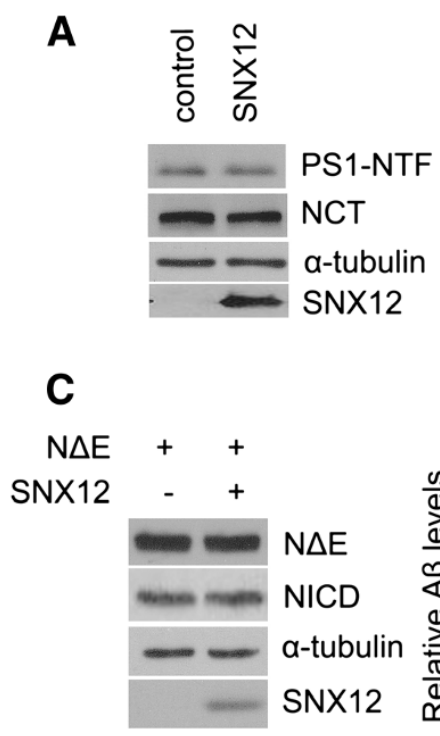

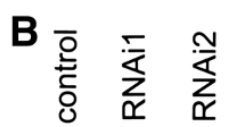
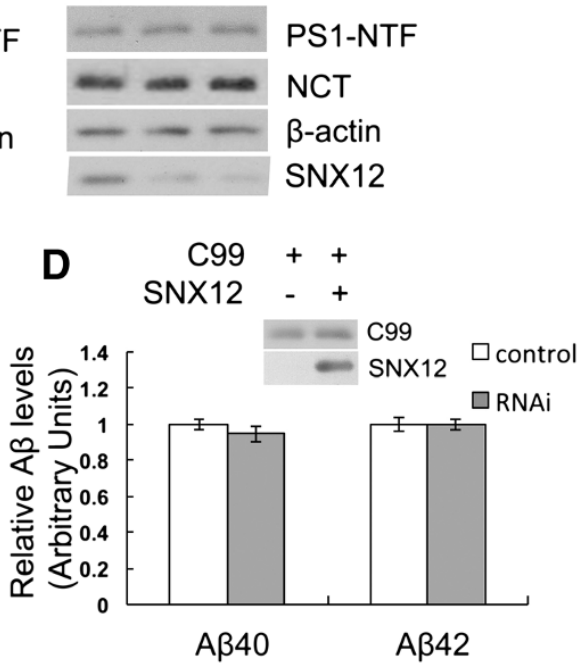

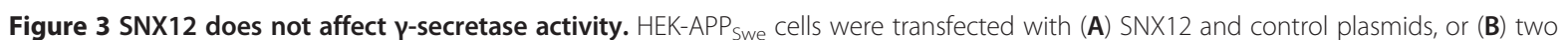
SNX12 siRNAs (1 and 2) and a control scrambled siRNA. Two $\gamma$-secretase components, PS1-NTF and nicastrin (NCT), were analyzed by Western blot. (C) HEK 293 T cells were first transfected with Notch N $\Delta$ E. After splitting equally, cells were transfected with SNX12 (+) or control (-) plasmids. Notch N $\Delta$ E and NICD in cell lysates were analyzed by Western blot. (D) HEK 293 T cells were first transfected with APP $\beta C T F / C 99$. After splitting equally, cells were transfected with SNX12 (+) or control (-) plasmids. Transfected C99 and SNX12 in cell lysates were analyzed by Western blot. $A \beta 40$ and $A \beta 42$ in conditioned media were assayed by ELISA. $N=4$.

\section{Discussion}

$A \beta$ is generated from its precursor APP through sequential cleavages first by $\beta$-secretase/BACE1 and then by $\gamma$-secretase, during their highly regulated trafficking within the cell. Dysregulation in the intracellular trafficking of these proteins may alter a proper interaction between APP and its two secretases, thereby affecting A $\beta$ production and contributing to disease pathogenesis. The putative $\beta$-secretase, BACE1, cycles between the secretory pathway compartments while BACE1 activity resides in both the secretory pathway and the endosomes. The intracellular trafficking of BACE1 may be affected by molecules that interact with it: some studies found that BACE1 can interact with reticulon/Nogo proteins, whose increased expression can block BACE1 in the ER that has a neutral $\mathrm{pH}$ environment and thus inhibit BACE1 activity in $A \beta$ generation [13-15]. In addition, Golgi-localized $\gamma$-ear-containing ARF-binding (GGA) proteins interact with BACE1 and regulate its trafficking between the late Golgi and early endosomes; depletion of GGA proteins increases the accumulation of BACE1 in the acidic early endosome for enhanced BACE1 stability and cleavage of APP [16-18]. More recently, a SNX family member, SNX6, has also been found to be associated with BACE1 and a reduction of SNX6 results in elevated steady-state levels of BACE1 as well as increased retrograde transport of BACE1 in the endocytic pathway, causing increased $A \beta$ generation [19].
In this study, we demonstrate that SNX12, another SNX family member, also interacts with BACE1 and affects the $\beta$-cleavage of APP. Although the steady-state level of BACE1 was not affected upon modulation of SNX12, downregulation of SNX12 resulted in increased BACE1 endocytosis and $A \beta$ generation, similar to that of SNX6; and overexpression of SNX12 reduced the production of $A \beta$. Importantly, we found that SNX12 was abundantly expressed in brain tissues and the level of SNX12 was dramatically decreased in the brain of $\mathrm{AD}$ patients when compared to that of controls, suggesting a direct link between SNX12 alteration and AD pathology.

SNX family members share a conserved PX motif that acts as a phosphoinositide-binding site for targeting the SNX protein to phosphoinositide-enriched membranes [28]. These proteins have been proposed to play a role in membrane trafficking and protein sorting [20-22]. In addition to SNX12 and SNX6 which interact with BACE1 and affect APP processing/ $A \beta$ generation, several other SNX members such as SNX17 [23] and SNX33 [24] have also been found to mediate APP processing/A $\beta$ generation through regulating the intracellular trafficking of APP. Together, these results suggest that SNX members may participate in $\mathrm{AD}$ pathology through modulating the trafficking of various $\mathrm{AD}$-associated proteins, which deserves further investigation. 
A

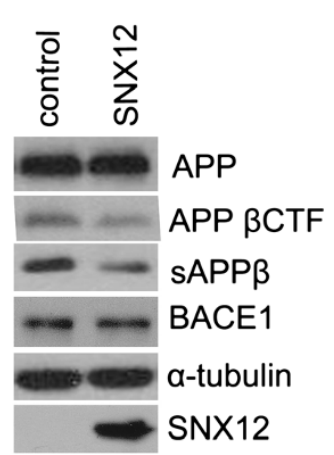

C

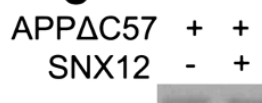

SNX12 - +

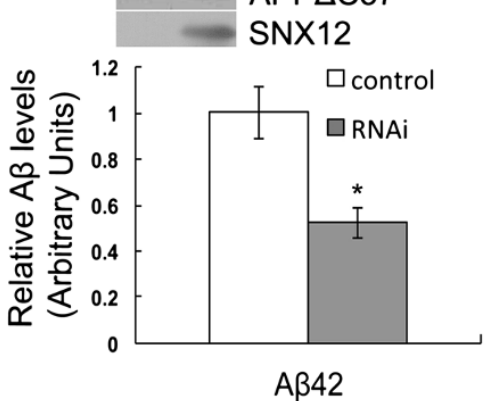

B

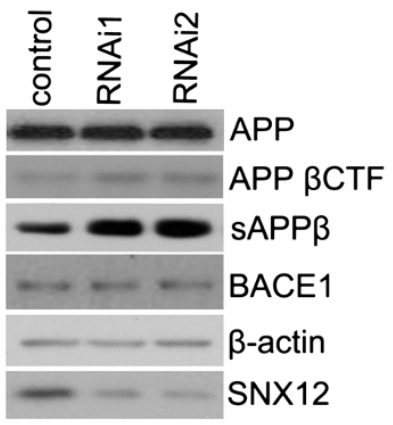

D

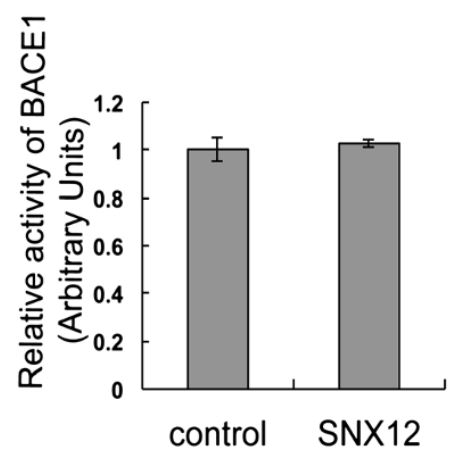

Figure 4 SNX12 affects $\beta$-processing of APP but not BACE1 level or activity. SH-SY5Y cells were transfected with (A) SNX12 and control plasmids, or (B) two SNX12 siRNAs (1 and 2) and a control scrambled siRNA. SAPP $\beta$ in conditioned media and total APP, APP $\beta$ CTF and BACE1 in cell lysates were analyzed by Western blot. (C) HEK 293 T cells were first transfected with APP $\Delta$ C57. After splitting equally, cells were transfected with SNX12 (+) or control (-) plasmids. Transfected APP $\Delta$ C57 and SNX12 in cell lysates were analyzed by Western blot. A 42 in conditioned media were assayed by ELISA. $N=4$, *: $p<0.05$. (D) SH-SY5Y cells were transfected with SNX12 and control plasmids. Cell lysates were assayed for BACE1 activity using a commercial kit. $\mathrm{N}=3$.

\section{Conclusion}

Our studies have demonstrated that SNX12 may participate in AD pathology by interacting with BACE1, thereby regulating BACE1 intracellular trafficking and BACE1-mediated $\beta$-processing of APP in A $\beta$ production. The reduction of SNX12 in the brain of AD patients may accelerate the endocytosis of BACE1 and lead to increased $A \beta$ generation. As BACE1 represents a favored target for $\mathrm{AD}$ intervention, inhibition of BACE1mediated $\beta$-processing of APP by regulating SNX12 might provide an alternative strategy for developing $\mathrm{AD}$ therapeutics.

\section{Methods}

Cell culture, plasmids and transfection

HEK293T and SH-SY5Y cells were maintained in DMEM (Hyclone) supplemented with 10\% FBS (Hyclone) and 1\% penicillin/streptomycin. HEK cells stably expressing human APP Swedish mutations (HEK-APP Swe $_{\text {) were }}$ maintained in the same media with the addition of $400 \mu \mathrm{g} / \mathrm{mL}$ G418 (Invitrogen). Hela cells were maintained in RPMI-1640 (Hyclone) supplemented with 10\% FBS and $1 \%$ penicillin/streptomycin. Maintenance of N2a cells stably expressing human APP695 (N2a-APP) was as previously reported [29]. Primary neurons derived from APP/ PS1/tau triple transgenic mice collected at postnatal day 0 were cultured in Neurobasal medium supplemented with B-27 (Invitrogen).

The pCI-neo-SNX12/myc plasmid and the pCI-neo control plasmid were kindly provided by Dr. Wanjin Hong. The BACE1-HA plasmid was kindly provided by Dr. Riqiang Yan. The APP $\beta$ CTF (containing the last 99 carboxyl-amino acids, C99) and $\Delta$ C57 (lacking the last 57 carboxyl-terminal amino acids) fragments were inserted into the pcDNA3.1-Myc/His plasmid (Invitrogen) to generate plasmids. The SNX12-EGFP plasmid was constructed by subcloning SNX12 into the pEGFP$\mathrm{N} 1$ plasmid (Clontech). Notch $\mathrm{N} \Delta \mathrm{E}$ plasmid was as previously reported $[27,30]$.

Transient transfection was performed by using TurboFect reagent (Fermentas), following the manufacturer's protocol. 


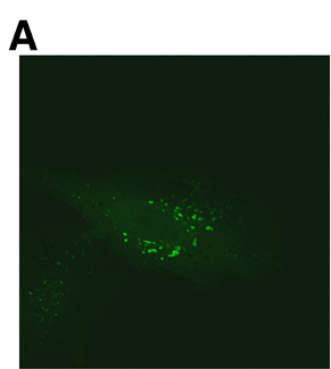

SNX12-EGFP

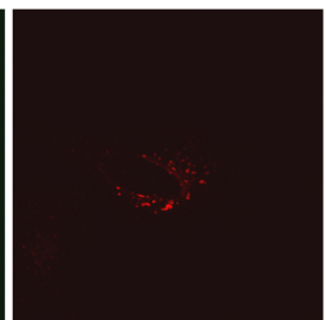

BACE1-HA

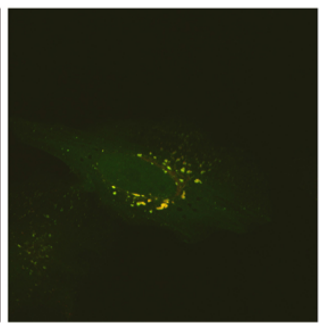

Merge

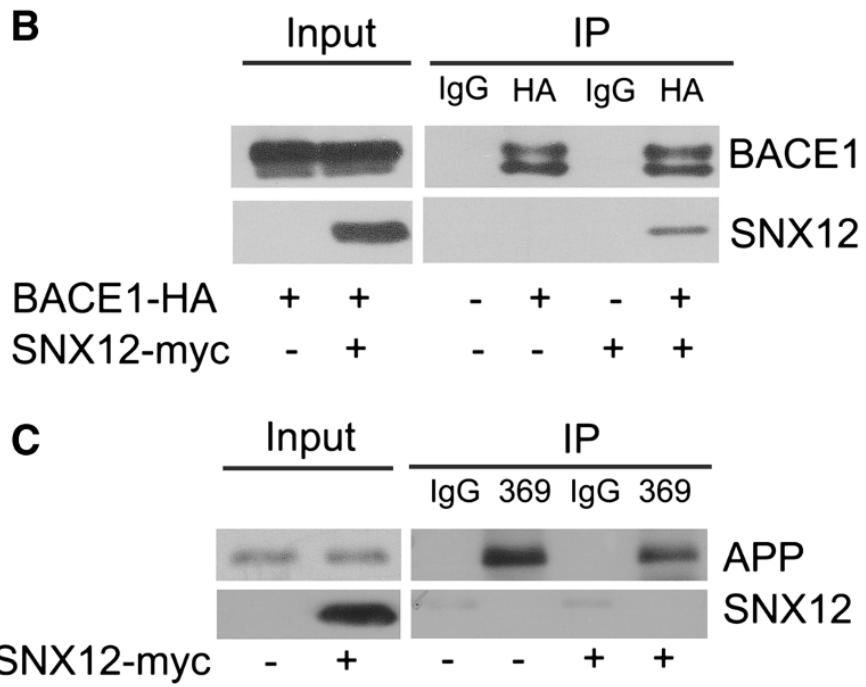

D

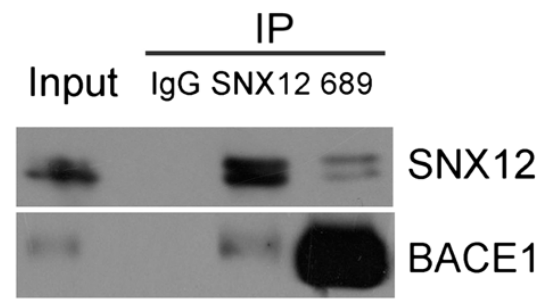

Figure 5 SNX12 interacts with BACE1. (A) HeLa cells were co-transfected with SNX12-EGFP (in green) and BACE1-HA. Cells were then fixed, permeabilized and immunostained sequentially with primary antibodies against HA and secondary antibodies conjugated with Alexa Fluor 594 (to indicate BACE1, in red). Samples were examined by a fluorescence confocal microscope. (B) BACE1-HA was co-transfected with control (-) or SNX12-Myc (+) into HEK 293T cells. Equal protein amounts of cell lysates were used for immunoprecipitation (IP) with an anti-HA antibody or control IgG. Immunoprecipitated proteins were subjected to Western blot with anti-HA or anti-Myc antibodies to detect BACE1 or SNX12,

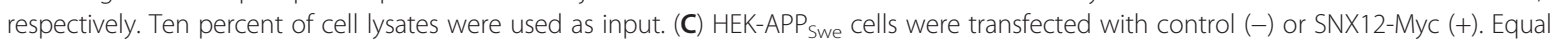
protein amounts of cell lysates were subjected to IP with control IgG or the anti-APP antibody 369. Immunoprecipitated proteins and input were subjected to Western blot. (D) Equal protein amounts of SH-SY5Y cell lysates were subjected to IP with control IgG, anti-SNX12 antibody, or the anti-BACE1 antibody 689. Immunoprecipitated proteins and input were subjected to Western blot analysis.

\section{Antibodies and western blot}

Antibodies used in this study include: anti-Myc antibody (9E10) from Santa Cruz Biotechnology; anti-HA and anti-SNX12 antibodies from Gene Tex; anti- $\alpha$-tubulin and anti- $\beta$-actin antibodies and control IgG from Sigma; anti-A $\beta$ antibody (6E10) from Covance; and anti-EEA1 and anti-cd63 antibodies from Abcam. Anti-BACE1 antibody 689 and anti-APP antibody 369 were kindly provided by Dr. Huaxi Xu. Anti-BACE1 antibody 3D5 was kindly provided by Dr. Robert Vassar.

Cells were lysed in a lysis buffer containing $10 \mathrm{mM}$ Tris- $\mathrm{HCl}$ (pH 7.8), $1 \mathrm{mM}$ EDTA, $150 \mathrm{mM} \mathrm{NaCl}, 1 \%$ Nonidet P-40 and supplemented with a protease inhibitor mixture. Equal protein amounts of cell lysates were 

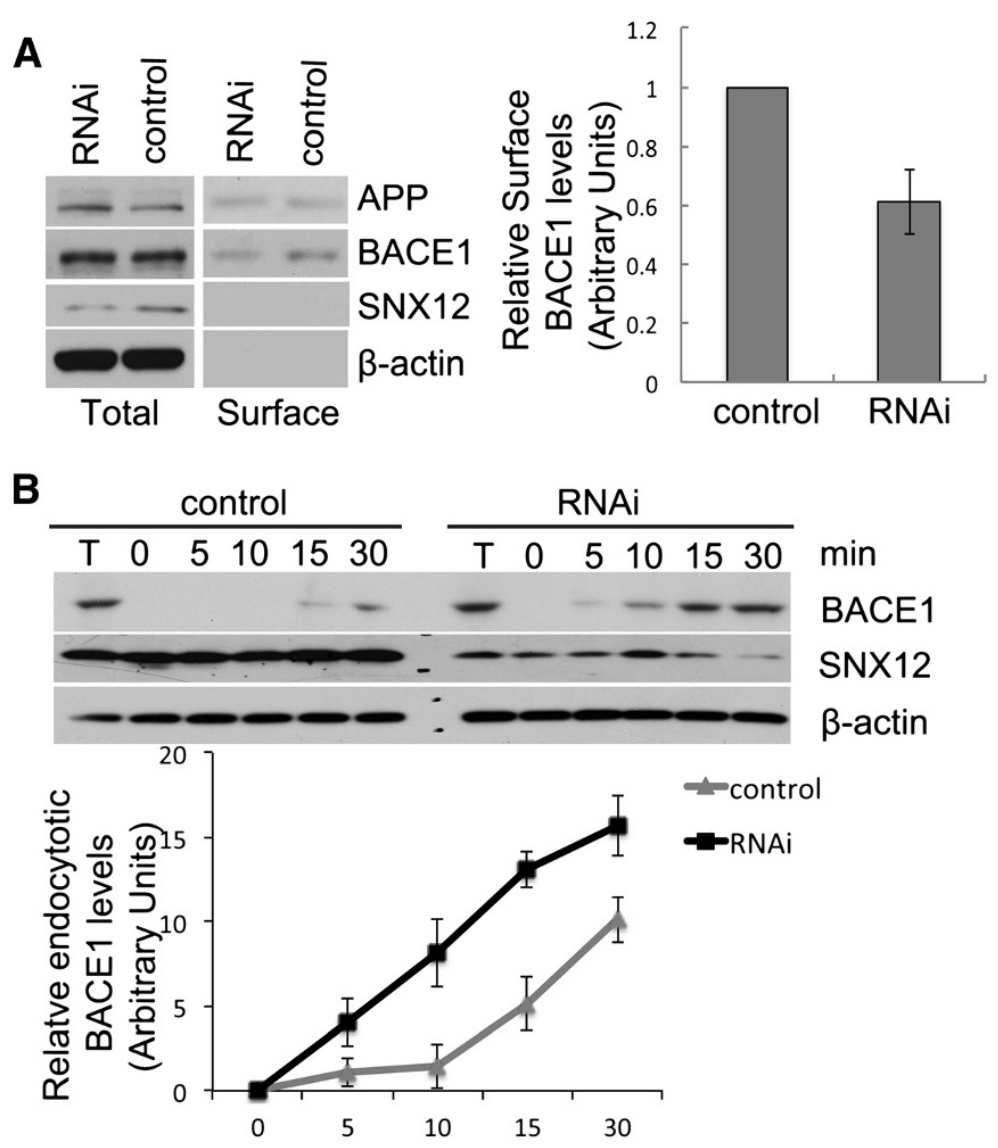

Figure 6 Downregulation of SNX12 accelerates the endocytosis of BACE1 and decreases the cell surface level of BACE1. (A) After RNAi downregulation of SNX12, SH-SY5Y cells were subjected to biotinylation. Cell lysates were affinity-precipitated with streptavidin-agarose beads to pull down biotinylated proteins that were at the cell surface. The levels of biotinylated BACE1 and APP, as well as their total protein levels, were analyzed by Western blot. Cell surface levels of BACE1 were quantified by densitometry and normalized to that of control (set as one arbitrary

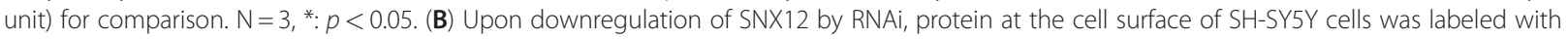
EZ-Link Sulfo-SS-Biotin. After chasing at $37{ }^{\circ} \mathrm{C}$ for the indicated times, cells were treated with glutathione at $4{ }^{\circ} \mathrm{C}$ to cleave biotin from remaining cell surface proteins. Cell lysates were affinity-precipitated with streptavidin-agarose beads. The levels of biotinylated (i.e. endocytosed) BACE1 were analyzed by Western blot. The levels of endocytotic BACE1 were quantified by densitometry and normalized to those of five percent of total (T) BACE1 (before chasing) for comparison. $\mathrm{N}=3,{ }^{*}: p<0.05$.

subjected to SDS-PAGE and Western blot with indicated antibodies.

\section{SNX12 RNA interference}

For RNA interference (RNAi) to downregulate human SNX12 expression, two SNX12 targeting siRNAs (1: 5'- ATGAGCTGGAGAGAGATAG-3'; and 2: 5'TGAACGCTGCCTACACATG-3') and a scrambled control siRNA (Invitrogen) were transfected into cells using Lipofectamine RNAiMAX reagent (Invitrogen), following the manufacturer's protocol.

\section{Lentivirus infection}

SNX12 shRNA and control lentiviral particles were purchased from Santa Cruz Biotechnology. These viruses were used to infect APP/PS1/tau primary neurons for $72 \mathrm{~h}$ before experiments.

\section{Immunoprecipitation}

Cells were lysed in a lysis buffer. Cell lysates were precleared with rProtein A sepharose (GE) at $4{ }^{\circ} \mathrm{C}$ for $1 \mathrm{~h}$ and then incubated with rProtein $\mathrm{A}$ sepharose and the indicated antibodies or IgG at $4{ }^{\circ} \mathrm{C}$ overnight. Immunoprecipitated proteins were analyzed by Western blot.

\section{$A \beta$ assay}

To detect the total level of secreted $A \beta$, cells were transfected for 24-48 $\mathrm{h}$ and then incubated with DMEM for 4-6 h. Conditioned media was then collected and incubated with trichloroacetic acid $(1: 9 \mathrm{v} / \mathrm{v})$ overnight at $4{ }^{\circ} \mathrm{C}$ for protein precipitation. Precipitated proteins were subjected to Western blot with the anti-A $\beta$ antibody $6 \mathrm{E} 10$. Alternatively, Conditioned media were assayed by ELISA to detect $A \beta 40$ and $A \beta 42$, using commercial ELISA kits (Invitrogen). 


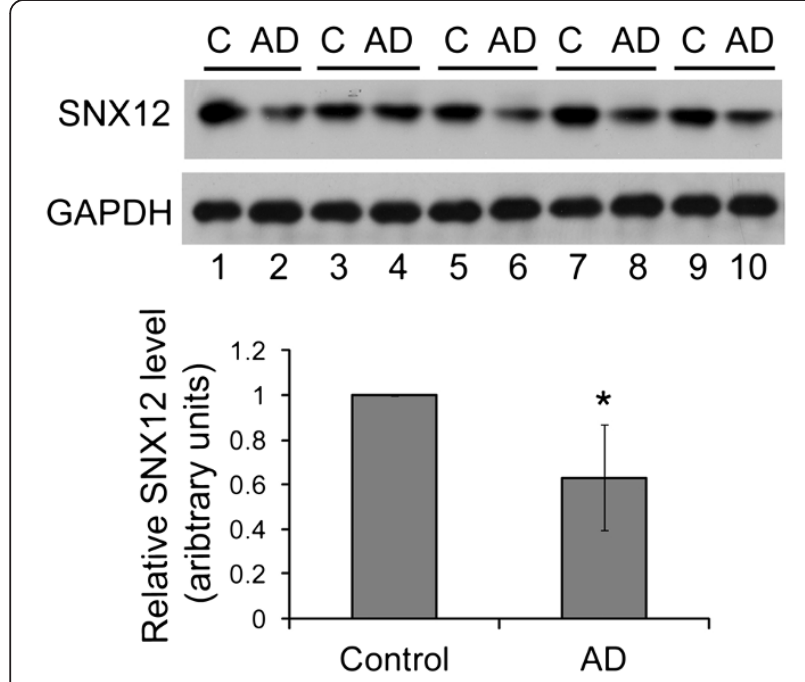

Figure 7 The level of SNX12 is decreased in AD brains. Equal amounts of protein lysates from the brains of AD patients and age/ sex matched controls (C) were analyzed for SNX12 by Western blot. Protein levels were quantitated by densitometry and normalized to those of GAPDH for statistical comparison to those of controls. Lane numbers are the same as numbers in Table 1. $\mathrm{N}=5,{ }^{*}: p<0.05$.

\section{BACE1 activity assay}

The in vitro BACE1 activity was assayed by using the $\beta$-Secretase Activity Assay Kit, Fluorogenic (Calbiochem), following the manufacturer's protocol.

\section{Immunofluorescence}

Treated cells were fixed in 4\% paraformaldehyde and permeabilized with $0.2 \%$ Triton-X100. Cells were then incubated with the indicated primary antibodies, followed by incubation with Alexa 594-conjugated secondary antibody (Invitrogen). Specimens were examined with a ZEISS LSM 5 Exciter confocal microscope and images were captured using the ZEN software.

\section{Cell surface biotinylation}

Treated cells were washed with ice-cold phosphatebuffered saline containing $1 \mathrm{mM}$ each of $\mathrm{CaCl}_{2}$ and $\mathrm{MgCl}_{2}$, and incubated at $4{ }^{\circ} \mathrm{C}$ with $0.5 \mathrm{mg} / \mathrm{mL}$ SulfoNHS-LC-biotin (Thermo Scientific, Rockford, IL). Cells were then lysed and lysates were affinity-precipitated with streptavidin-agarose beads (Thermo Scientific). Biotinylated proteins were subjected to Western blot analysis.

\section{Cell surface protein endocytosis assay}

Cells were first biotinylated with cleavable EZ-Link Sulfo-SS-Biotin (Thermo Scientific). After chasing at $37{ }^{\circ} \mathrm{C}$ for the indicated times, cells were treated with cold glutathione buffer at $4{ }^{\circ} \mathrm{C}$ to cleave biotin from cell surface proteins. The remaining biotinylated proteins represent the endocytosed proteins and were affinity-
Table 1 Human brain samples used in this study

\begin{tabular}{llll}
\hline Number* & Case & Sex & Age \\
\hline 1 & Non-AD & Female & 82 \\
2 & AD & Female & 83 \\
3 & Non-AD & Female & 76 \\
4 & AD & Female & 78 \\
5 & Non-AD & Male & 83 \\
6 & AD & Male & 83 \\
7 & Non-AD & Male & 68 \\
8 & AD & Male & 67 \\
9 & Non-AD & Male & 78 \\
10 & AD & Male & 76 \\
\hline
\end{tabular}

*: Numbers are the same as lane numbers in Figure 7.

precipitated with streptavidin-agarose beads for further Western blot analysis.

\section{SNX12 level in human brains}

Brain cortical region samples of AD patients and ageand sex-matched controls were kindly provided by Dr. Yong Shen. More detailed information of these samples was listed in Table 1. Samples were lysed in RIPA buffer and equal protein amounts of samples were subjected to Western blot to detect the level of SNX12.

\section{Statistical analysis}

Two-tailed paired $t$-test was carried out for statistical analysis.

\section{Abbreviations}

A $\beta$ : $\beta$-amyloid; APP: $\beta$-amyloid precursor protein; BACE1: $\beta$-site APP cleaving enzyme 1; AD: Alzheimer's disease; CTF: Carboxyl terminal fragment; SAPP $\beta$ : NCT Nicastrin; NTF: amino-terminal fragment; PS1: Presenilin 1; PS2: Presenilin 2; RNAi: RNA interference; APP $\beta$ : Soluble; SNX: Sorting nexin; SNX12: Sorting nexin 12.

\section{Competing interests}

The authors declare that they have no competing interests.

\section{Authors' contributions}

$Y Z, Y W, J Y, X W$ and $Y Z$ performed experiments; $X Z$ analyzed data; $Y$-WZ designed research, analyzed data and wrote the paper. All authors have read and approved the final manuscript.

\section{Acknowledgements}

We thank Drs. Yong Shen for human brain specimen, Wanjin Hong for SNX12 and control plasmids, Riqiang Yan for BACE1 plasmid, Huaxi Xu for the 689 and 369 antibodies, and Robert Vassar for the 3D5 antibody. This study was supported by grants from the Alzheimer's Association, National Natural Science Foundation of China (30973150, 81161120496 and 81000540), 973 Prophase Project (2010CB535004), Natural Science Foundation of Fujian Province of China (2009J06022 and 2010J01235), the Program for New Century Excellent Talents in Universities (NCET), the Fundamental Research Funds for the Central Universities, and Fok Ying Tung Education Foundation.

\section{Author details}

${ }^{1}$ Fujian Provincial Key Laboratory of Neurodegenerative Disease and Aging Research, College of Medicine, Xiamen University, Xiamen, Fujian 361005, People's Republic of China. ${ }^{2}$ School of Pharmaceutical Sciences, Xiamen 
University, Xiamen, Fujian 361005, People's Republic of China. ${ }^{3}$ Neurodegenerative Disease Research Program, Sanford-Burnham Medical Research Institute, La Jolla, CA 92037, USA.

Received: 16 March 2012 Accepted: 24 May 2012

Published: 18 June 2012

\section{References}

1. Zheng $\mathrm{H}, \mathrm{Koo} E \mathrm{H}$ : Biology and pathophysiology of the amyloid precursor protein. Mol Neurodegener 2011, 6:27.

2. Hardy J, Selkoe DJ: The amyloid hypothesis of Alzheimer's disease: progress and problems on the road to therapeutics. Science 2002, 297:353-356.

3. Shankar GM, Walsh DM: Alzheimer's disease: synaptic dysfunction and Abeta. Mol Neurodegener 2009, 4:48

4. Koffie RM, Hyman BT, Spires-Jones TL: Alzheimer's disease: synapses gone cold. Mol Neurodegener 2011, 6:63.

5. Sinha S, Anderson JP, Barbour R, Basi GS, Caccavello R, Davis D, Doan M, Dovey HF, Frigon N, Hong J, et al: Purification and cloning of amyloid precursor protein beta-secretase from human brain. Nature 1999, 402:537-540.

6. Vassar R, Bennett BD, Babu-Khan S, Kahn S, Mendiaz EA, Denis P, Teplow DB Ross $S$, Amarante $P$, Loeloff $R$, et al: Beta-secretase cleavage of Alzheimer's amyloid precursor protein by the transmembrane aspartic protease BACE. Science 1999, 286:735-741.

7. Yan R, Bienkowski MJ, Shuck ME, Miao H, Tory MC, Pauley AM, Brashier JR, Stratman NC, Mathews WR, Buhl AE, et al: Membrane-anchored aspartyl protease with Alzheimer's disease beta-secretase activity. Nature 1999, 402:533-537.

8. Lau KF, McLoughlin DM, Standen C, Miller CC: X11 alpha and x11 beta interact with presenilin-1 via their PDZ domains. Mol Cell Neurosci 2000, 16:557-565.

9. Walter J, Fluhrer R, Hartung B, Willem M, Kaether C, Capell A, Lammich S, Multhaup G, Haass C: Phosphorylation regulates intracellular trafficking of beta-secretase. J Biol Chem 2001, 276:14634-14641.

10. Huse JT, Pijak DS, Leslie GJ, Lee VM, Doms RW: Maturation and endosomal targeting of beta-site amyloid precursor protein-cleaving enzyme. The Alzheimer's disease beta-secretase. J Biol Chem 2000, 275:33729-33737.

11. Huse JT, Liu K, Pijak DS, Carlin D, Lee VM, Doms RW: Beta-secretase processing in the trans-Golgi network preferentially generates truncated amyloid species that accumulate in Alzheimer's disease brain. J Biol Chem 2002, 277:16278-16284.

12. Cole SL, Vassar R: The Alzheimer's disease beta-secretase enzyme, BACE1. Mol Neurodegener 2007, 2:22

13. He W, Lu Y, Qahwash I, Hu XY, Chang A, Yan R: Reticulon family members modulate BACE1 activity and amyloid-beta peptide generation. Nat Med 2004, 10:959-965.

14. Murayama KS, Kametani F, Saito S, Kume H, Akiyama H, Araki W: Reticulons RTN3 and RTN4-B/C interact with BACE1 and inhibit its ability to produce amyloid beta-protein. Eur J Neurosci 2006, 24:1237-1244.

15. Shi Q, Prior M, He W, Tang X, Hu X, Yan R: Reduced amyloid deposition in mice overexpressing RTN3 is adversely affected by preformed dystrophic neurites. J Neurosci 2009, 29:9163-9173.

16. He X, Li F, Chang WP, Tang J: GGA proteins mediate the recycling pathway of memapsin 2 (BACE). J Biol Chem 2005, 280:11696-11703.

17. Tesco G, Koh YH, Kang EL, Cameron AN, Das S, Sena-Esteves M, Hiltunen M, Yang $\mathrm{SH}$, Zhong Z, Shen Y, et al: Depletion of GGA3 stabilizes BACE and enhances beta-secretase activity. Neuron 2007, 54:721-737.

18. Wahle T, Prager K, Raffler N, Haass C, Famulok M, Walter J: GGA proteins regulate retrograde transport of BACE1 from endosomes to the trans Golgi network. Mol Cell Neurosci 2005, 29:453-461.

19. Okada H, Zhang W, Peterhoff C, Hwang JC, Nixon RA, Ryu SH, Kim TW: Proteomic identification of sorting nexin 6 as a negative regulator of BACE1-mediated APP processing. FASEB J 2010, 24:2783-2794.

20. Cheever ML, Sato TK, de Beer T, Kutateladze TG, Emr SD, Overduin M: Phox domain interaction with Ptdlns(3)P targets the Vam7 t-SNARE to vacuole membranes. Nat Cell Biol 2001, 3:613-618.

21. Ellson CD, Gobert-Gosse $S$, Anderson KE, Davidson $K$, Erdjument-Bromage $H$, Tempst $P$, Thuring JW, Cooper MA, Lim ZY, Holmes AB, et al: Ptdlns(3)P regulates the neutrophil oxidase complex by binding to the $\mathrm{PX}$ domain of p40(phox). Nat Cell Biol 2001, 3:679-682.
22. Xu Y, Seet LF, Hanson B, Hong W: The Phox homology (PX) domain, a new player in phosphoinositide signalling. Biochem J 2001, 360:513-530.

23. Lee J, Retamal C, Cuitino L, Caruano-Yzermans A, Shin JE, van Kerkhof $P$, Marzolo MP, Bu G: Adaptor protein sorting nexin 17 regulates amyloid precursor protein trafficking and processing in the early endosomes. J Biol Chem 2008, 283:11501-11508.

24. Schobel S, Neumann S, Hertweck M, Dislich B, Kuhn PH, Kremmer E, Seed B, Baumeister R, Haass C, Lichtenthaler SF: A novel sorting nexin modulates endocytic trafficking and alpha-secretase cleavage of the amyloid precursor protein. J Biol Chem 2008, 283:14257-14268.

25. Oddo S, Caccamo A, Shepherd JD, Murphy MP, Golde TE, Kayed R, Metherate R, Mattson MP, Akbari Y, LaFerla FM: Triple-transgenic model of Alzheimer's disease with plaques and tangles: intracellular Abeta and synaptic dysfunction. Neuron 2003, 39:409-421.

26. Mizutani R, Nakamura K, Kato N, Aizawa K, Miyamoto Y, Torii T, Yamauchi J, Tanoue A: Expression of sorting nexin 12 is regulated in developing cerebral cortical neurons. J Neurosci Res 2011, 90:721-731.

27. Schroeter EH, Kisslinger JA, Kopan R: Notch-1 signalling requires ligandinduced proteolytic release of intracellular domain. Nature 1998, 393: 382-386.

28. Voos W, Stevens TH: Retrieval of resident late-Golgi membrane proteins from the prevacuolar compartment of Saccharomyces cerevisiae is dependent on the function of Grd19p. J Cell Biol 1998, 140:577-590.

29. Zhang YW, Liu S, Zhang X, Li WB, Chen Y, Huang X, Sun L, Luo W, Netzer WJ, Threadgill R, et al: A Functional mouse retroposed gene Rps23r1 reduces Alzheimer's beta-amyloid levels and tau phosphorylation. Neuron 2009, 64:328-340

30. Zhang YW, Wang R, Liu Q, Zhang H, Liao FF, Xu H: Presenilin/gammasecretase-dependent processing of beta-amyloid precursor protein regulates EGF receptor expression. Proc Natl Acad Sci USA 2007, 104:10613-10618.

doi:10.1186/1750-1326-7-30

Cite this article as: Zhao et al:: Sorting nexin 12 interacts with BACE1 and regulates BACE1-mediated APP processing. Molecular Neurodegeneration 2012 7:30.

\section{Submit your next manuscript to BioMed Central and take full advantage of:}

- Convenient online submission

- Thorough peer review

- No space constraints or color figure charges

- Immediate publication on acceptance

- Inclusion in PubMed, CAS, Scopus and Google Scholar

- Research which is freely available for redistribution 